\title{
Subsídios histórico-filosóficos para o ensino do modelo atômico de Dalton
}

Marcos Antônio Gatto marcosagatto@hotmail,com Universidade Tecnológica Federal do Paraná (UTFPR), Apucarana, Paraná, Brasil

José Bento Suart Júnior

suart@utfpr.edu.br
orcid.org/0000-0003-1162-1032

Orcid.org/0000-0003-1162-1032 Paraná (UTFPR), Apucarana, Paraná, Brasil

Enio de Lorena Stanzani eniostanzani@utfpr.edu.br orcid.org/0000-0002-1787-0534 Universidade Tecnológica Federal do Paraná (UTFPR), Apucarana, Paraná, Brasil

\section{RESUMO}

O objetivo desse trabalho é buscar na história e filosofia da ciência subsídios para o ensino do modelo atômico de Dalton, com intuito de contribuir para a mudança do atual cenário de ensino, encarado como abstrato pela maioria dos alunos. Utilizando a historiografia da ciência, os principais aspectos históricos relativos à constituição do modelo atômico de Dalton foram levantados, apontando assim os principais conceitos que devem ser trabalhados por meio de uma abordagem histórica para tornar o processo de ensino e aprendizagem mais próximo e significativo para o estudante. Os resultados encontrados apontam para a necessidade de discussão de aspectos históricos e conceituais anteriores às proposições de Dalton, assim como a discussão de experimentos ligados ao estudo dos gases que levaram o cientista à proposição de uma perspectiva quantitativa para a constituição atômica da matéria. Para além da importância de Dalton como propositor de uma perspectiva quantitativa, conclui-se a necessidade de transformá-lo em um personagem constituinte de uma longa história de conceitos sobre a matéria, do qual o próprio foi herdeiro e defensor.

PALAVRAS-CHAVE: Ensino de Química. O modelo atômico de Dalton. História da Ciência. 


\section{INTRODUÇÃO}

O ensino de Química desenvolvido na maior parte das escolas públicas do Brasil não tem obtido sucesso. Segundo especialistas, uma das razões desse insucesso pode ser atribuída ao perfil adotado, repleto de informações descontextualizadas, formato que não possibilita desenvolver nos estudantes, atitudes ou maneiras de analisar criticamente a realidade em que vivem. Desta forma, o método de ensino "tradicional" não se adequada às necessidades da sociedade atual e, por conseguinte, não atinge o objetivo central do ensino de Ciências na Educação Básica, o de formar um cidadão crítico e atuante na sociedade (RIBEIRO; MESQUITA, 2012).

Os Parâmetros Curriculares Nacionais para o Ensino Médio - PCNEM (BRASIL, 2000) mostram que os conteúdos a serem trabalhados no ensino de Química não se resumem apenas à transmissão de informação, uma vez que, segundo Nunes e Adorni (2010), devem possibilitar a relação com o cotidiano do aluno, seus objetivos e sua rotina.

É indispensável, portanto, que o professor de Química leve em consideração o contexto que os alunos estão inseridos, de forma que a realidade dos estudantes seja contemplada nas aulas de Química, possibilitando ao aluno aprender e a fazer diferentes figuras da realidade e assim torná-lo protagonista de sua aprendizagem (RIBEIRO; MESQUITA, 2012).

Nesse contexto, diversos pesquisadores do Ensino de Química desenvolveram investigações com o objetivo de evidenciar as principais dificuldades de estudantes e professores no desenvolvimento de processos de ensino de aprendizagem de conteúdos químicos na Educação Básica (SANTOS et al., 2013; MELO; LIMA-NETO, 2013; QUADROS et al., 2011). Dentre essas pesquisas, destacamos o estudo de França, Marcondes e Carmo (2009), na qual os autores discutem a dificuldade de compreensão dos estudantes frente ao conteúdo de Estrutura Atômica, enfatizada, principalmente, pelo grau de abstração exigido no entendimento dos conceitos envolvidos.

Segundo Mortimer (1995), os alunos do Ensino Médio, quando iniciam as aulas de Química, trazem ideias bem diferentes sobre a natureza atômica em relação àquelas aceitas cientificamente. Os estudantes não são capazes de fazer relações entre os modelos atomistas e o comportamento dos materiais nas inúmeras transformações, por exemplo.

Essas pesquisas evidenciam, portanto, que o conceito de átomo é distante da realidade do aluno e, para que a compreensão dos conceitos envolvidos se torne possível, é preciso mobilizar a criação de modelos, os quais tornam-se ferramentas fundamentais utilizadas para compreender o mundo, cujo acesso real é muito abstrato (FRANÇA; MARCONDES; CARMO, 2009).

Os problemas e dificuldades destacados pelas investigações referentes ao ensino e a aprendizagem do conteúdo de Modelos Atômicos e mais especificamente do Modelo Atômico de Dalton, devem-se, em partes, à falta de material de apoio adequado disponível aos professores da Educação Básica.

Os materiais didáticos disponibilizados acabam influenciando a visão dos alunos, uma vez que, na maioria das vezes, os livros didáticos referem-se o modelo atômico de Dalton utilizando a analogia da bola de bilhar, maciça e indivisível. 
Segundo Miranda e colaboradores (2015), esse tipo de abordagem acontece porque os livros didáticos se tornaram fontes diluídas de conhecimento por haver vários interesses envolvidos e sua produção.

Apesar das dificuldades encontradas no ensino de atomismo, o modelo atômico de Dalton é um conceito de grande importância para o ensino de Química, pois apresenta aos alunos as ideias iniciais sobre atomismo e, como destaca Filgueiras (2004), é um dos marcos primordiais presentes na história da Química.

A teoria atômica de Dalton é um dos marcos fundamentais da Química do século XIX. Ao contrário das cogitações abstratas de tantas outras teorias sobre a constituição da matéria, a sua se originou de uma combinação de intuição teórica e observações de laboratório, sendo respaldada diretamente por seus estudos sobre os gases. A obtenção de resultados confiáveis nas determinações de pesos atômicos levou muitas décadas. Com pesos atômicos confiáveis e o esclarecimento definitivo da diferença entre átomos $e$ moléculas, a teoria passou a ter aceitação universal e tornou-se um dos alicerces da Química. (FILGUEIRAS, 2004, p. 44).

Nesse sentido, compreender os conceitos relacionados ao modelo atômico de Dalton é essencialmente importante para os estudantes, pois além de ser um dos alicerces da Química, seus conceitos influenciaram outros modelos que surgiram no estudo do átomo, além de terem contribuído historicamente para o desenvolvimento da Química que temos hoje.

Considerando as dificuldades e problemas apontados pelas pesquisas em Ensino de Química/Ciências acerca dos processos de ensino e aprendizagem dos conceitos relacionados à teoria atômica de Dalton e buscando, dessa forma, verificar os materiais disponíveis para o ensino desse conceito, foi realizado um levantamento bibliográfico nos principais periódicos brasileiros encontrados na internet e classificados pela CAPES (Coordenação de Aperfeiçoamento de Pessoal de Nível Superior) no sistema WEBQualis, com índices de avaliação A1, A2, B1 e B2 na área de Ensino, publicados entre no período de 1980-2016. Os artigos foram pesquisados individualmente utilizando a palavra-chave 'Dalton' e, quando o acervo da revista não era encontrado em seu site especifico, foi utilizado o indexador Scielo.

Ao todo foram pesquisadas 150 revistas, sendo encontrados 43 artigos relacionados ao modelo atômico de Dalton. Em seguida foram criadas categorias, a fim de identificar os assuntos com maior predominância encontrados na pesquisa bibliográfica, conforme mostra a Figura 1. 
Figura 1 - Assuntos abordados nos artigos pesquisados

ASSUNTOS POR ARTIGO

QUIMICA NO ENSINO FUNDAMENTAL $2 \%$
PROFESSORMEDIADOR NO ENSINO $2 \%$
OUTROS

ETICA E DESENVOLVIMENTO DE CONCEITOS CIENTIFICOS 2\%

ESTRATEGIAS E RECURSOS PARA O ENSINO $26 \%$

ENTREVISTA 2\%

ENSINO DE CIENCIAS E TEATRO $\mathbf{5 \%}$

DISCUSSÄOTEORICA $23 \%$

CONCEPÇÖES ALTERNATIVAS $\quad \mathbf{9 \%}$

APRESENTAÇÄO DERECURSOS PARA O ENSINO DE CONCEITOS $7 \%$

\begin{tabular}{lll} 
ANALISELD & $5 \%$ \\
\hline
\end{tabular}

ANALISEDEARTIGOS E LIVROS SOBRE HC $\mathbf{5 \%}$

Fonte: Autoria própria (2017).

Já o Quadro 1, apresentado a seguir, mostra detalhadamente a relação entre a classificação e o número total de revistas pesquisadas, o número de revistas que possuem artigos sobre o modelo atômico de Dalton e o número de artigos sobre o modelo atômico de Dalton.

Quadro 1 - Correlação entre classificação WEBQualis com número de revistas pesquisadas, número de revistas com artigos sobre o modelo atômico de Dalton e número de artigos sobre o modelo atômico de Dalton

\begin{tabular}{c|c|c|c}
\hline Qualis & $\begin{array}{c}\text { No de revistas } \\
\text { pesquisadas }\end{array}$ & $\begin{array}{c}\text { No de revistas que } \\
\text { possuem artigos sobre o } \\
\text { modelo atômico de Dalton }\end{array}$ & $\begin{array}{c}\text { No de artigos sobre } \\
\text { o modelo atômico } \\
\text { de Dalton }\end{array}$ \\
\hline A1 & 10 & 1 & 1 \\
\hline A2 & 15 & 0 & 0 \\
\hline B1 & 60 & 4 & 40 \\
\hline B2 & 65 & 1 & 2 \\
\hline
\end{tabular}

Fonte: Autoria própria (2017).

Os dados da Tabela 1 mostram que a maior parte dos artigos publicados sobre o modelo atômico de Dalton foi encontrado em revistas classificadas como B1, tendo poucos trabalhos publicados em revistas A1 ou B2. Não foi encontrado nenhum artigo presente em revistas A2.

Em relação à classificação dos artigos na principal categoria, objeto de estudo dessa pesquisa, denominada "Estratégias e recursos para o ensino", enquadramse onze artigos, os quais sugerem propostas ou estratégias direcionadas para o ensino de Química, como atividades experimentais (CAMPOS; SILVA, 2004), recursos multimídia (SILVA; MACHADO; SILVEIRA, 2015; OLIVEIRA et al., 2013), ensino para alunos com necessidades educacionais especiais (PEREIRA; BENITE; BENITE, 2011), sequências didáticas (RIBEIRO; ROCHA; BRUNO, 2015), dentre outras, o que têm como objetivo comum promover o ensino de conceitos científicos relacionados aos modelos atômicos, apresentando ferramentas e as principais dificuldades relacionadas ao ensino desse conteúdo.

Porém, nenhum artigo tem enfoque exclusivamente no ensino do modelo atômico de Dalton, uma vez que, na maioria dos trabalhos citados, seu modelo é 
apenas parte integrante das propostas. Dessa forma, torna-se necessário o desenvolvimento de propostas direcionadas a esse tema, com o objetivo de superar as dificuldades encontradas no ensino de Química relacionado ao atomismo, especialmente às proposições de John Dalton.

Mortimer (1995) salienta que uma das alternativas para os professores superarem essas dificuldades enfrentadas no ensino de atomismo é a utilização da História da Ciência, por fornecer um paralelismo, de acordo com o autor:

A importância desse paralelismo reside no fato de podermos mostrar aos alunos, através da história da ciência, que os modelos que eles propõem se assemelham a modelos históricos que foram superados por um mais simples e racional, um modelo que admite que as partículas se movimentem no espaço vazio e explica várias transformações dos materiais em termos de mudanças no arranjo, na organização, na energia e no movimento das partículas, sem a necessidade de lhes atribuir todas as propriedades macroscópicas. (MORTIMER, 1995, p. 26).

Martins (2007) afirma que a História e Filosofia da Ciência (HFC) contém uma extensão de estudos e pesquisas em que suas especificidades e bases teóricas vêm evoluindo com o passar do tempo, além de apresentar profundas contribuições para a Didática das Ciências por conter uma forte área de conhecimento. Assim, a HFC pode ser utilizada na construção de conceitos estruturantes de uma teoria, ajudando o aluno a compreender as origens e os fundamentos que envolvem a construção de um determinado conceito.

É evidente que o objetivo do ensino não é que os alunos tracem os passos de grandes cientistas, mas que sejam capazes de questionar o processo de construção do conhecimento científico, no qual a HFC é capaz de conduzir para uma abordagem que envolva questionamentos e leve a produção do conhecimento científico.

Desse modo, o objetivo deste trabalho é buscar subsídios histórico-filosóficos que sejam capazes de auxiliar os professores no ensino do modelo atômico de Dalton, possibilitando aos alunos um ensino mais próximo e significativo de seu contexto, superando as barreiras destacadas no ensino de atomismo.

\section{METODOLOGIA}

A fim de alcançar os objetivos traçados anteriormente, a metodologia utilizada nesse trabalho foi a historiografia da ciência.

O método historiográfico é capaz de mostrar com clareza os diversos elementos presentes no mundo científico, relacionando-o com o mundo externo. Por ter caráter crítico, revela as bases epistemológicas históricas, políticas e axiológicas construídas nas narrativas históricas (VIDEIRA, 2007).

Por meio da historiografia é possível fazer uma análise crítica de obras já publicadas, procurando compreender quais foram às concepções e interesses científicos por parte do narrador a respeito do fato descrito, investigando seus objetivos e influências, como também seu público alvo. Dessa forma podemos compreender a ciência como ela realmente foi elaborada e produzida, e também seus processos de transições históricas e científicas (VIDEIRA, 2007). 
Um aspecto importante na historiografia refere-se aos níveis utilizados para distinguir a história. Segundo Kragh (2001), a história pode se distinguir em dois níveis chamados de $\mathrm{H} 1$ e H2. A história $\mathrm{H} 1$ se refere à descrição de fenômenos ou fatos reais que aconteceram no passado, é objetiva, sendo interpretada como o próprio passado ou fenômenos passados. $\mathrm{O}$ único acesso que temos a $\mathrm{H} 1$ são seus fragmentos que foram passados por fontes informativas. A história H2 é apresentada como uma análise da realidade de $\mathrm{H} 1$, de forma a investigar historicamente seus resultados. Nesse sentido, a história H2 é um estudo da própria $\mathrm{H} 1$, de modo similar em que o objeto de estudo das ciências naturais é a natureza (KRAGH, 2001).

Se o objeto de estudo é a História da Ciência, são possíveis dois conceitos chamados de C1 e C2. Ciência 1 (C1) é atribuída a um conjunto de informações empíricas e formais acerca da natureza, desse modo a ciência é caracterizada em um produto acabado. A Ciência 2 (C2) se refere ao comportamento e atividades dos cientistas. Assim, C2 é a ciência com desempenho humano, podendo ou não conduzir a um verdadeiro e objetivo saber a respeito da natureza.

Segundo Kragh (2001), a historiografia pode ser definida como o profissionalismo da escrita sobre a história, ou seja, representações dos fatos passados descritos por historiadores.

Outro aspecto importante referente à historiografia é a análise de fontes, que tem como objetivo determinar a sua independência e fiabilidade. As fontes são habitualmente distinguidas, segundo Kragh (2001), em primárias e secundárias. Fontes primárias são aquelas provenientes da época em que revela a informação e têm ligação direta com a realidade histórica (cartas, registros, diários, manuscritos etc.). Já as fontes secundarias são produzidas em épocas posteriores e têm como origem fontes anteriores, ou seja, as fontes primárias. Dessa maneira, dependendo da análise, uma fonte pode assumir o papel de primária ou secundária.

Assim, com o intuito de auxiliar os professores com um material de qualidade contendo fatos e fundamentos com recortes históricos confiáveis, será desenvolvida essa abordagem utilizando principalmente fontes secundárias, a fim de alcançar os objetivos propostos.

\section{RESULTADOS E DISCUSSÃO}

Para atender os objetivos desse trabalho, foi produzido um texto histórico destacando os principais conceitos científicos acerca do atomismo, desde a Grécia antiga até John Dalton propor seu modelo atômico. Compreender o contexto histórico em que o atomismo desenvolveu-se, desde seus primórdios até a teoria atômica de Dalton, é de fundamental importância, pois possibilita entender a evolução do conceito atômico ao longo da história, além de evidenciar as contribuições de diversos cientistas para a construção da Teoria Atômica. Desse modo, o texto a seguir oferece subsídios que podem auxiliar professores e futuros professores no ensino do modelo atômico de Dalton. 


\section{O DESENVOLVIMENTO DO MODELO ATÔMICO DE DALTON POR MEIO DE UM ESTUDO HISTORIOGRÁFICO: OS ANTECEDENTES DE JOHN DALTON}

Viveram na Grécia antiga, aproximadamente nos séculos VII e V a.C, os primeiros pensadores a fazer suposições sobre a matéria, conhecidos como filósofos pré-socráticos. Seus estudos se destinavam sobre a origem, transformações, princípios da natureza da matéria e suas relações com o divino (MARR, 2008).

Uma das principais contribuições dos gregos para a Química foi o conceito de elemento. Empédocles, assim como outros filósofos (490 a.C.- 430 a.C.), ao invés de propor um único princípio para a matéria, propôs um número limitado de elementos. Segundo ele os objetos e seres seriam compostos por diferentes proporções de quatro elementos: terra, água, ar e fogo. Essa teoria ficou conhecida como a Teoria dos Quatro elementos.

Além destas contribuições filosóficas e cientificas para a origem da matéria, Leucipo e Demócrito, ambos gregos, criaram o pensamento cientifico conhecido como átomo. Segundo Marr (2008), para Leucipo e Demócrito os átomos seriam partículas pequenas e indivisíveis que dividiam toda a matéria, possuindo um contínuo movimento no vácuo, idealizando uma teoria atômica.

Contra as ideias atomistas, Aristóteles (384 a.C. - 322 a.C.) rejeita o vácuo, pois o mesmo estaria em desacordo com a sua teoria do movimento, sendo inconcebível na filosofia eleática. Além disso, inventa o éter com o objetivo de suprir as eventuais lacunas causadas entre os quatro elementos que compõem a matéria. Por ser uma figura de autoridade em todos os campos da ciência, sua aceitação da teoria dos quatro elementos e sua rejeição do pensamento atomista influenciou a Química/Alquimia por muitos anos.

O pensamento aristotélico ganhou grande prestígio em sua época. A igreja, uma de suas seguidoras, aderiu à filosofia aristotélica orientando a evolução científica e renascentista sobre sua influência (MARR, 2008). A teoria dos quatro elementos foi aceita pelos cientistas por quase 2000 anos porém, mesmo após a oposição do atomismo por Aristóteles, alguns filósofos ainda defendiam o atomismo, como foi o caso de Epicuro (341 a.C.-270 a.C.).

O grego e filósofo Epicuro pregava uma física muito semelhante à de Demócrito, pois foi influenciado por um de seus alunos. Seu atomismo continha apenas algumas modificações: no modelo de Demócrito, os átomos poderiam assumir qualquer tamanho, já para Epicuro os átomos continham partículas de tamanho agregado e se movimentam com a velocidade do pensamento. Influenciado por Epicuro, o poeta e filósofo Lucrécio (340 a.C.-268 a.C.) expôs em seus trabalhos as ideias atomistas de Demócrito.

As obras de Epicuro contém um aspecto materialista, apresentando muitos dos conceitos químicos que temos hoje. Mesmo após as ideias de Epicuro e Lucrécio não terem êxito aos seus contemporâneos, o atomismo democritiano não desapareceu por completo, pois foi sendo considerado como uma alternativa para muitos filósofos, inclusive seguidores de Aristóteles, causando grande surpresa (MARR, 2008).

O atomismo da antiguidade é considerado real e mecanicista, pois os átomos propostos não possuem um modelo que interprete a natureza. Essas entidades 
consideradas reais pretendiam explicar fenômenos naturais em termos de movimentos, transposições, rearranjos, justaposições e separação de partículas.

Até então, o conceito de átomo não tinha espaço no âmbito científico, foi somente com as ideias mecanicistas no século XVI que esse conceito começou a ganhar força, dando início a um novo atomismo científico. Surgiram assim às primeiras teorias corpusculares ou atomísticas elaboradas por vários cientistas como René Descartes (1596-1650), Pierre Gassendi (1592-1655), Robert Boyle (1627-1691) e Sir Isaac Newton (1642-1727).

Descartes (1596-1650) afirmava que somente as relações matemáticas poderiam compreender a matéria. Descartes considerava que a matéria e a extensão eram a mesma coisa. Em geral, sua teoria corpuscular considerava um corpo ou uma parte da matéria como algo que se move em conjunto, não diferenciando matéria e extensão, negando, dessa forma, a existência do vazio. Assim, seus corpúsculos eram caracterizados por conter diferentes massas e movimentos sobre um meio material (éter). Para Descartes, as características dos materiais seriam guiadas por leis matemáticas (VIANA, 2007).

O século XVII seguia com uma forte corrente repleta de seguidores da filosofia mecanicista da natureza, dentre eles o filósofo e atomista Pierre Gassendi. Pierre Gassendi (1592-1655) é tido como o filósofo que restaurou o atomismo na modernidade, criticando o epicurismo tradicional. Segundo o filósofo, o universo não poderia ser explicado apenas pelas concepções atomistas, pelo contrário, deveria assumir a existência de Deus. Nesse contexto, juntamente com Boyle, adequou o mecanicismo para explicar a matéria e, assim, o atomismo foi deixando de ser considerado uma doutrina pagã, o que possibilitou o avanço das ideias atomistas (VIANA, 2007).

A principal figura da Química mecanicista foi Robert Boyle (1627-1691), que é visto como responsável por destacar as teorias de Gassendi e Descartes. Por ter grande ligação com os dados macroscópicos, procurava utilizar seus experimentos para desenvolver suas teorias e fundamentos, os quais foram derivados das ideias de Lord Bacon.

Boyle acreditava que a matéria era constituída por partículas que poderiam se agregar de diversas formas e aglomerados, combinando-se de diversas maneiras possíveis. As últimas partículas da matéria seriam entidades completamente pequenas, sólidas e fisicamente indivisíveis. Assumindo o vácuo, as partículas formariam aglomerados coesos que seriam resistentes às operações químicas, tornando muito difícil de se romperem. Os corpúsculos secundários seriam responsáveis pelas características imutáveis presentes nos materiais e poderiam se combinar formando substâncias compostas que se recombinariam facilmente (ALFONSO-GOLDFARB et al., 2016).

As ideias de Boyle sobre a composição e transformação da matéria abalaram as visões da Química, sendo possível explicar as observações sobre as transformações da matéria. Porém, suas ideias não foram muito aceitas, predominando aquelas do flogístico como principal constituinte da matéria.

Influenciado pelos trabalhos de Boyle, já no final do XVII, o físico e mecanicista Isaac Newton (1642-1727) ganhou grande destaque por conseguir relacionar os aspectos experimentais aos matemáticos. Ele desenvolveu a mecânica clássica e os princípios matemáticos envolvidos em sua abordagem. A mecânica newtoniana 
foi utilizada para explicar os fenômenos físicos, químicos e todos os fenômenos naturais (MARR, 2008). Newton buscou utilizar as ideias corpusculares para explicar os fenômenos ocorridos em escala microscópica. Acreditava na hipótese de que, assim como havia uma força entre os planetas, também poderia existir uma força entre duas partículas. A base de sua teoria era explicar as interações entre as partículas e as propriedades dos materiais, utilizando suas leis universais para o movimento dos corpos.

Similar à teoria corpuscular de Boyle, Newton também acreditava na hipótese de transmutação de matéria sobre a constituição de corpos. As últimas partículas da matéria seriam comuns e encontradas em diferentes substâncias, como o ouro e a prata, das quais falaremos mais adiante. No modelo newtoniano seria assumido que as partículas eram estáticas, ocorrendo movimentos apenas quando houvessem mudanças nas condições. Assim, o posicionamento relativo das partículas não sofreria alterações, mudando apenas a distância entre as partículas.

Neste sentido, os três estados físicos da matéria dependeriam da posição relativa das partículas: no estado sólido as partículas estariam mais próximas se comparadas ao estado líquido e no líquido mais próximas do que no estado gasoso (VIANA, 2007).

No século XVIII podemos destacar que a ciência foi fortemente influenciada pelas obras de Boyle e Newton no desenvolvimento do corpuscularismo, por muitos chamados de atomismo. Com a proposta newtoniana, o ar liberado a partir da fermentação ou pelo calor dos corpos que os químicos denominavam como fixos seria composto por partículas que se repelem de forma mútua.

Outra grande figura na história da Química foi Antoine-Laurent Lavoisier (1743-1794), que é considerado como um dos mais importantes químicos da história. Para Marr (2008), a extensa obra de Lavoisier é encarada como uma Revolução Química. Inovou com a teoria do oxigênio, além de fazer experimentos envolvendo a combustão do diamante, $\mathrm{CO}_{2}$, combustão do fósforo, enxofre, aquecimento de metais. Publicou em seu livro o tratado elementar da Química que expõe sua teoria atômica, produtos químicos desconhecidos, aparelhos e métodos de equipamentos. Além dessas contribuições, Lavoisier propôs 33 elementos por meio de métodos analíticos (MARR, 2008).

Com suas descobertas Lavoisier consegue banir da Química três princípios elementares: a terra, a água e o flogisto, pois, até o momento, esses três constituintes eram admitidos composição da matéria e suas transformações (ALFONSO-GOLDFARB et al., 2016). Lavoisier faz uma verdadeira revolução na Química, admitindo o ar como um componente da matéria, além de propor uma nova definição para elemento: passa a admitir que elemento seria todo material obtido no ponto final de uma análise química e propõe a definição operacional do conceito.

As ideias de Lavoisier e seus colaboradores introduziram na Química uma nova maneira de pensar a composição da matéria e suas transformações. As novas definições de elemento químico conduziram os químicos a trabalharem na hipótese de existir um grande número de elementos. A quantificação de massa envolvida nas transformações conduziu a uma nova descoberta essencial, a de uma nova teoria atômica (ALFONSO-GOLDFARB et al., 2016). 


\section{JOHN DALTON E A PROPOSIÇÃO DO MODELO ATÔMICO CORPUSCULAR}

John Dalton nasceu em 6 de dezembro de 1766 na aldeia de Eaglesfield, em Cumberland, região mais ao norte da Inglaterra, sendo um dos seis filhos de Joseph e Deborah Dalton. Seu pai era tecelão e agricultor e pertencia, assim como seu o filho, à comunidade religiosa quakers (grupo religioso com origem no movimento protestante britânico do século XVII), o que explica a simplicidade e vida espartana do pai da teoria atômica (MARR, 2011).

Dalton fez seus primeiros estudos na escola da aldeia, realizando em 1777 o curso de navegação e mensuração. Já em 1778, lecionou em uma escola quakers em Cumberland e depois em Kendal com seu irmão, passando suas horas de lazer estudando latim, grego, francês, matemática e filosofia natural (MARR, 2011). Dalton começou a estudar meteorologia e tornou-se obcecado por registrar os mínimos detalhes do tempo a cada dia. Apesar de ser cego para cores, seu interesse em fenômenos meteorológicos o levou a descrever a aurora boreal (STRATHERN, 2002).

Em 1793 mudou-se para Manchester para lecionar Matemática e Filosofia Natural no New College a pedido de seu amigo, o filosofo John Gough (1757-1825). Um ano após sua chegada em Manchester, Dalton começou a lecionar Química, principalmente utilizando como referência o livro texto Elements of Chemistry tradução inglesa do tratado de Antoine Laurent Lavoisier.

Conforme afirma Viana (2007), quando Dalton começou a ensinar Química, teve a necessidade de estudar e compreender profundamente o trabalho de Lavoisier. Tendo esses conhecimentos influenciado fortemente na consolidação de sua teoria atômica.

Em 1794 tornou-se associado da Manchester Literary and Philosophical Society, entidade fundada em 1781 pelo médico e aluno de Joseph Black (17281799) e Thomas Percival (1740-1804), sociedade essa atuante até os dias de hoje.

Na Manchester Literary and Philosophical Society, Dalton foi secretário de 1800 a 1816, e presidente de 1817 a 1844, apresentando cerca de 116 trabalhos científicos, os quais foram divulgados no periódico Memoirs of the Literary and Philosophical Society of Manchester, fundado em 1785 e ainda hoje publicado. A sede da sociedade foi destruída em dezembro de 1840 nos bombardeios a Manchester, e junto com ela grande parte dos escritos e instrumentos científicos de Dalton.

Dalton sofreu de paralisia, morrendo em Manchester no dia 27 de julho de 1844 , aos 77 anos. Seu enterro reuniu cerca de 40.000 pessoas, homenagem até então que nenhum cientista havia recebido. Os materiais de pesquisa de Dalton foram confiados a W. C. Henry, e este os doou à Manchester Society.

A obra de John Dalton é um marco para a história da Química, que com simplicidade e dedicação se tornou um dos grandes químicos da história. Antes de nos aprofundarmos sobre sua vida e obra, vamos entender como foi importante o estudo da solubilidade dos gases para a sua teoria atômica. No final do século XVIII, já era conhecida a composição da atmosfera por alguns constituintes: o gás nitrogênio (maior quantidade), gás oxigênio, gás carbônico e vapor de água (VIANA; PORTO, 2007). 
Dalton tinha grande interesse por fenômenos atmosféricos, fato que acabou conduzindo-o a uma série de perguntas sobre a composição da atmosfera. Porém, uma questão estava presente dentro da comunidade científica: os fluidos gasosos estariam combinados quimicamente na atmosfera ou eles se encontravam misturados? Outro aspecto que não estava claro por parte dos cientistas era sobre a hipótese da atmosfera ser uma mistura. Questionavam-se por que os gases não se separavam em camadas conforme sua densidade.

Os questionamentos de Dalton foram um grande exemplo de que na maioria das vezes a ciência avança não a partir de experimentos, mas sim de ideias concebidas previamente pelos cientistas e só depois testadas experimentalmente (FILGUEIRAS, 2004). Mediante estas questões, Dalton procurou solucionar os problemas utilizando os conceitos corpusculares de Newton, que em sua visão eram mais apropriados com sua realidade.

A ciência do século XVIII foi fortemente influenciada pela obra de Newton, sendo divulgada principalmente por livros textos e outros materiais populares daquela época. Por meio de livros destinados à sua divulgação, Dalton teve seus primeiros contatos com as ideias do grande filósofo natural Isaac Newton (VIANA; PORTO, 2007).

Para Newton, a matéria seria formada por diferentes partículas organizadas de forma prioritária entre os elementos, chamada de "ultimate particles", consideradas as menores partículas da matéria. Essa visão de partículas organizadas da matéria foi inspirada nas ideias de Robert Boyle. Boyle uniu as concepções provindas do atomismo grego sobre a matéria ser constituída de partículas indivisíveis (que chamamos de átomos), com as ideias aristotélicas da conservação da matéria como um todo, conhecida como mínima naturalia. Essa junção de ideias resultou em uma teoria corpuscular com propriedades especiais (VIANA; PORTO, 2007). No contexto de Newton, acreditava-se na existência de um único fluido gasoso, chamado de ar comum, sendo considerado um elemento por apresentar como característica a homogeneidade.

Com o passar dos anos, ao longo do século XVIII, os químicos pneumanicistas descobriram que a atmosfera era constituída por vários tipos de ares, surgindo a necessidade de propor novos modelos para explicar esta variedade (VIANA; PORTO, 2007). Dalton procurava entender como a atmosfera poderia ser constituída por vários gases de diferentes densidades e apresentar aspecto homogêneo. Sua primeira explicação formulada para esse fato foi considerada como uma variação elegante do modelo de Newton (VIANA; PORTO, 2007). Newton em suas obras Opticks (questão 31 e Livro 2, dos Principia - proposição $23^{\circ}$ ) afirma que cada gás se comporta como um fluido elástico newtoniano, agindo como se os demais gases não estivessem na mistura. Dalton então tem uma livre interpretação desse enunciado.

Dalton descreve seu modelo influenciado pelas ideias de Newton, afirmando que quando dois fluidos elásticos são denotados por partículas chamadas de A e B misturadas não existe repulsão entre as partículas de forma mútua, ou seja, as partículas provindas de $A$ não se afastam com as partículas de $B$, fato que não ocorre se estivessem apenas entre a mesma espécie (VIANA; PORTO, 2007).

As afirmações destacadas anteriormente correspondem à primeira teoria das misturas gasosas propostas por Dalton. Com base na sua teoria das misturas 
gasosas, Dalton passou a explicar o fato de o aumento da quantidade de um dos componentes em uma mistura gasosa não influenciar qualquer efeito sobre a pressão de outro. Esses enunciados formulados por Dalton ficaram conhecidos como a lei de Dalton das pressões parciais. Os estudos iniciais de Dalton a respeito das misturas de gases caracterizaram a primeira teoria das misturas gasosas, a qual permitiu explicar a maneira como os gases estariam organizados em uma atmosfera com diversos constituintes.

Conforme preconizava o modelo de Dalton: os átomos iguais não poderiam ficar próximos, pois se repeliam; os átomos diferentes não notavam qualquer efeito uns sobre os outros; volumes que aparentavam ser iguais possuíam números diferentes de partículas.

A primeira teoria das misturas gasosas de Dalton enfrentou diversas críticas por parte dos filósofos da época, como no caso do ex-professor de Dalton, John Gough, que criticava a aleatoriedade de seus princípios. Contudo, essa primeira teoria das misturas gasosas permitiu que o amigo de Dalton, William Henry (17741836), compreendesse a relação entre a pressão exercida por um gás e sua solubilidade em um líquido, estabelecendo a lei conhecida como lei de Henry, a qual afirmava que em uma determinada temperatura, a massa de gás absorvido pela água era diretamente proporcional à pressão. Essa lei teve grande influência na proposição da teoria atômica de Dalton.

Henry se ocupava em estudar a produção de água gaseificada, pois tinha uma indústria química em sua família. Já Dalton investigava a solubilidade dos gases de acordo com a sua primeira teoria de misturas gasosas. Dalton e Henry teriam estudado inicialmente a solubilidade do gás carbônico em água, pois, até então, era o único gás cuja solubilidade em água havia sido estudada.

Como consequência das determinações de solubilidade do gás carbônico em água, foi constatada por Henry uma enorme diferença das quantidades desse gás absorvidas por água quando se mantinha a pressão e temperatura constantes. Henry afirmava que as causas das variações eram desconhecidas por ele, até que Dalton sugere que as variações certamente eram dependentes das quantidades de resíduos de gás que não foram dissolvidos. Henry, ao repetir seus experimentos utilizando diferentes proporções entre o gás e a água, confirma a hipótese sugerida por Dalton (VIANA; PORTO, 2007).

Os efeitos das variações presenciadas por Henry só ocorreram porque o gás carbônico não era extremamente puro, caso contrário não apresentaria variações. Porém, as técnicas utilizadas por ele não possibilitavam a preparação de gases muito puros, e assim a exata solubilidade do gás carbônico só poderia ser descoberta utilizando as análises dos gases misturados, mediante a aplicação da lei das pressões parciais de Dalton.

Após suas análises, Henry concluiu que a solubilidade dos gases em água seria um fenômeno de caráter mecânico, no qual a quantidade de gás absorvida seria proporcional à densidade do gás, levando em consideração somente o gás em questão, sem considerar influência de outros gases, caso estivessem misturados. Henry agora se mostra totalmente adepto à primeira teoria das misturas gasosas (pois inicialmente era contrário) conforme afirma Dalton: 
a saber: que cada gás, em qualquer mistura, exerce uma pressão distinta, a qual permanece a mesma se os demais gases forem retirados (DALTON, 1964, p.141 apud VIANA; PORTO, 2007, p.7).

Neste sentido, a forma utilizada por Henry para explicar o comportamento de cada componente da mistura gasosa é orientada somente por sua pressão, não levando em conta a quantidade de outros componentes, assumindo-se a validade da primeira teoria das misturas gasosas proposta por Dalton.

Estendendo sua pesquisa para outros gases, Henry descobriu que em determinada temperatura a massa de gás que era absorvida pela água era diretamente proporcional à sua pressão parcial. Esse enunciado ficou conhecido como lei de Henry. A importância da lei de Henry foi rapidamente reconhecida por Dalton, que a relacionou com sua primeira lei das misturas gasosas, juntamente com um modelo mecânico de dissolução de um gás em água. Quando Dalton considerou a solubilidade como um fenômeno de caráter mecânico, ela passou a ser dependente apenas da natureza dos gases dissolvidos e da sua pressão, assim os gases se difundiriam pelos poros da água (VIANA, 2007).

Durante a maior parte do ano de 1803, Dalton se concentrou em conciliar o fenômeno da solubilidade dos gases em água com um sistema mecânico, que era fundamentado na teoria atomista inspirada pelas concepções newtonianas que ele acreditava existir (VIANA, 2007). Expondo seu trabalho sobre solubilidade dos gases, publicado em 1805 e denominado "On the Absorpition of Gases by Water and Other Liquids", Dalton procura classificar a solubilidade dos gases de acordo com suas frações de solubilidade, feitas a partir de uma relação matemática.

\begin{abstract}
Se uma quantidade de água, livre de ar, for agitada em presença de qualquer tipo de gás que não se una quimicamente com a água, ela absorverá uma massa de gás igual a sua própria, ou então uma parte dela, igual a uma das seguintes frações, a saber: 1/8,1/27, 1/64, 1/125, etc. - sendo estas frações os cubos dos recíprocos dos números naturais 1, 2, 3, etc., ou seja, 1/1, 1/23, $1 / 33,1 / 43$, etc. $O$ mesmo gás será sempre absorvido de acordo como se mostra na tabela a seguir (DALTON, 1805 apud VIANA; PORTO, 2007, p. 8).
\end{abstract}

Segundo o próprio Dalton, a relação envolvendo o peso relativo e o número de partículas últimas do gás era algo totalmente novo na química (MARR, 2011). Procurando explicar os diversos valores de solubilidade, foi investigado por Dalton se as diferentes massas dos átomos não seriam o motivo para essas variações:

\footnotetext{
A maior dificuldade para contemplar a hipótese mecânica provém do fato de diferentes gases observarem diferentes leis. Por que a água não admite a mesma quantidade de qualquer tipo de gás? Esta questão eu tenho considerado devidamente, e embora ainda não ser capaz de me satisfazer completamente, estou quase persuadido de que essa circunstância depende do peso e do número das partículas ultimas dos diversos gases: aquelas cujas partículas são mais leves e simples são menos absorvíveis, e as outras são mais, conforme aumentam em peso e complexidade. (DALTON, 1805 apud VIANA; PORTO, 2007, p.8).
}

Consequentemente, após a publicação dessa afirmação, a tabela de massas atômicas relativas foi impressa e divulgada em seu artigo em 1805. Para registrar seus resultados sobre os átomos simples e compostos, Dalton precisou de símbolos. Porém, a simbologia proposta pelos alunos de Lavoisier em 1787 não teve muita aceitação por parte da sociedade científica, desse modo, Dalton cria 
seus próprios símbolos com formatos circulares de diferentes aspectos conforme ilustra a Figura 2 (MARR, 2011). Todos os estudos e experimentos sobre gases, executados por Dalton com bastante precisão, serviram como dados importantes para a elaboração de seu atomismo, como também para o estudo precursor da Físico-Química (MARR, 2011).

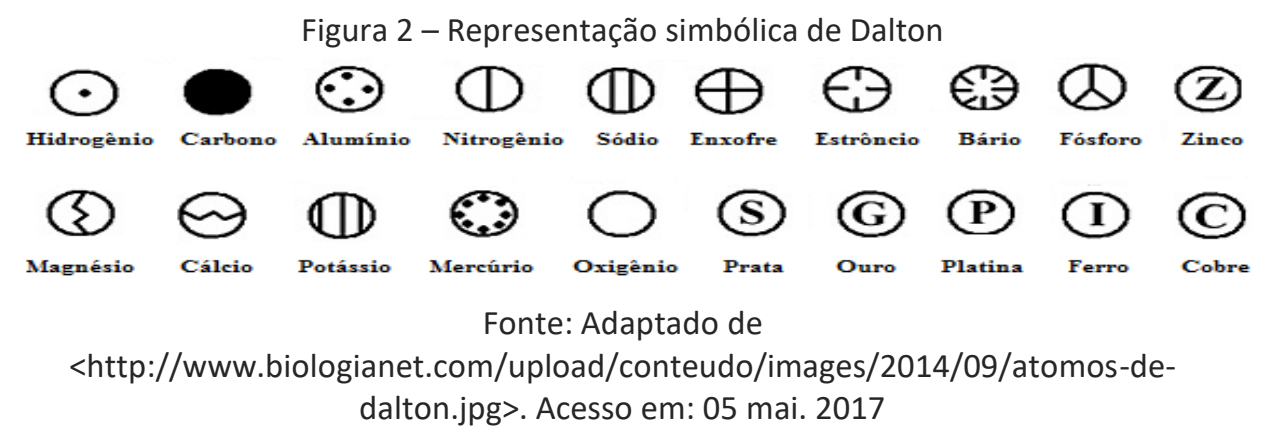

Surge então a necessidade de desenvolver um modelo para que Dalton fosse capaz de determinar as massas atômicas relativas. Esse modelo teria que explicar as combinações químicas, além de beneficiar a suposição de fórmulas para os compostos químicos.

Utilizando uma mistura de oxigênio e hidrogênio, Dalton buscou explicar as combinações químicas, alegando que ocorreria a repulsão entre os átomos de oxigênio e hidrogênio, resultando uma condição de equilíbrio na mistura dos gases. Contudo, se acaso acabasse esse equilíbrio, por alguma situação, aconteceria uma transformação, resultando na união entre os átomos de hidrogênio e oxigênio. Para ocorrer essa união seria necessário um estímulo como, por exemplo, uma faísca elétrica. Assim, após a combinação entre oxigênio e hidrogênio, encontraríamos uma mistura formada de vapor de água e oxigênio. Segundo Viana e Porto (2007), na possibilidade de continuarmos com as transformações químicas encontraríamos um agrupamento de pares obedecendo assim a chamada de regra da máxima simplicidade:

Caso fosse possivel dar prosseguimento as transformações, os átomos de
água e de oxigênio poderiam agora se agrupar em pares. No modelo proposto
por Dalton, as interações aconteceriam na sequência de um para um,
obedecendo a assim chamada regra da máxima simplicidade (VIANA; PORTO,
2007, p.9).

Segundo a regra da máxima simplicidade, proposta por Dalton, seriam possíveis vários tipos de combinações, essas chamadas de lei das proporções múltiplas. Sendo essa lei, quando dois corpos A e B se combinam, suas combinações ocorrem na seguinte sequência (Quadro 2): 
Quadro 2 - Sequência de combinações propostas por Dalton na Lei das Proporções Múltiplas

\begin{tabular}{|c|}
\hline 1 átomo de $A+1$ átomo de $B=1$ átomo de $C$ (binário) \\
1 átomo de $A+2$ átomos de $B=1$ átomo de $D$ (ternário) \\
2 átomos de $A+1$ átomo de $B=1$ átomo de $E$ (ternário) \\
1 átomo de $A+3$ átomos de $B=1$ átomo de $F$ (quaternário) \\
3 átomos de $A+1$ átomo de $B=1$ átomo de $G$ (quaternário)
\end{tabular}

Fonte: Autoria própria (2017).

Dalton desenvolveu um modelo combinatório, baseado em uma combinação preferencial 1:1, chamada de regra da máxima simplicidade, tornando possível propor fórmulas químicas:

1) quando só é possível uma combinação entre dois corpos, deve ser presumida uma combinação binária, a não ser que outra causa exija o contrário. 2) quando são possíveis duas combinações, uma será binária e a outra ternária. 3) quando são possíveis três combinações, uma será binária, as outras ternárias. 4) quando são possíveis quatro combinações, uma será binária, duas ternárias e uma quaternária. 5) um composto binário é sempre mais denso do que a simples mistura dos dois ingredientes. 6) um composto ternário será mais denso do que a mistura do composto binário e do composto simples que o formariam. 7) as regras e observações acima também se aplicam quando dois corpos, como $C$ e $D, D$ e $E$ etc. se combinam (MARR, 2011, p.202).

Desta forma, haveria vários tipos de geometrias que dependeriam da quantidade de átomos combinados e esses estariam dispostos de maneira a evitar a repulsão entre as partículas (VIANA; PORTO, 2007).

A consequência da hipótese de Dalton torna indiscutíveis as noções de proporção e combinações de unidades discretas, porém coloca em debate uma questão: Qual seria a formula correta? Os equivalentes químicos permitiam fazer relações entre corpos simples. Os átomos constituintes exigiam um número: Quantos átomos teriam um composto? Como determinar a proporção exata de átomos de hidrogênio que se unem com oxigênio? (BENSAUDE-VINCENT: STENGERS, 1992).

Para propor a primeira tabela de massas atômicas foi utilizado o mecanicismo para sugerir as fórmulas de átomos compostos, provenientes das combinações químicas. Além das fórmulas, foram empregadas as proporções de massa envolvidas nessas combinações (VIANA; PORTO, 2007).

Na época de Dalton, alguns autores já haviam publicado em suas obras alguns valores de massas atômicas relativas. Ele tinha conhecimento das análises de Lavoisier para a água, formada por $85 \%$ de oxigênio e $15 \%$ de hidrogênio em massa. Conhecia também as análises feitas por Austin para a amônia, formada por $80 \%$ de nitrogênio e $20 \%$ de hidrogênio em massa, e por fim das análises de Chenevix do anidrido sulfúrico, composto por $61,2 \%$ de enxofre e $38,8 \%$ de oxigênio em massa. Dalton também tomou posse dos experimentos de Lavoisier sobre a formação de óxidos de carbono (VIANA; PORTO, 2007). Assim, tinha em mãos uma variedade de valores que apontavam as proporções nas reações de formação das substâncias por ele estudadas.

Partindo desses valores, Dalton determinou as massas atômicas relativas, que eram mediadas pela regra da máxima simplicidade. Se recordarmos, o motivo que 
levou Dalton a investigar a causa dos diversos valores de solubilidade dos gases em água, foi justamente a diferença de massa entre os elementos químicos. Desta maneira, as combinações sucessivas entre os átomos ocorreriam na proporção 1:1, resultando em fórmulas químicas que indicavam as proporções de massas envolvidas nas transformações macroscopicamente observadas (VIANA; PORTO, 2007). A existência de vários óxidos de nitrogênio é um grande exemplo prático a ser considerado da aplicação da lei das proporções múltiplas.

Posteriormente, Dalton percebeu a possibilidade de aplicar a lei das proporções múltiplas à outros compostos, os hidrocarbonetos. O metano, por exemplo, chamado naquela época de gás hidrogênio carburado, seria formado por um átomo de carbono e dois de hidrogênio. Já o gás etileno, chamado de gás oleificante, seria formado por um átomo de carbono e um de hidrogênio. Desse modo, as bases teóricas e práticas da química e física dos gases, em termos quantitativos, estavam lançadas, tornando Dalton um dos precursores dos estudos quantitativos sobre gases (MARR, 2011).

A grande aplicabilidade da lei das proporções múltiplas foi declarada também por outros cientistas, como por exemplo de William Hyde Wollaston (1766-1828), o qual declarou, em 1808, que muitas de suas análises de sais, obtidas pelas reações de neutralização, poderiam ser explicadas a partir dos princípios da lei proposta por Dalton. Aos poucos, Dalton foi incorporando sua teoria, propondo ideias que até então não faziam parte dessa, como no caso das transformações químicas, afinidade química e também sobre o calórico defendido nas obras de Lavoisier.

A partir das ideias de Lavoisier sobre o calórico, Dalton estabelece que cada átomo simples ou composto possuiria uma atmosfera de calórico em seu entorno, conforme mostra a figura 3 .

Figura 3: Esquemas representativos das "atmosferas" de calórico

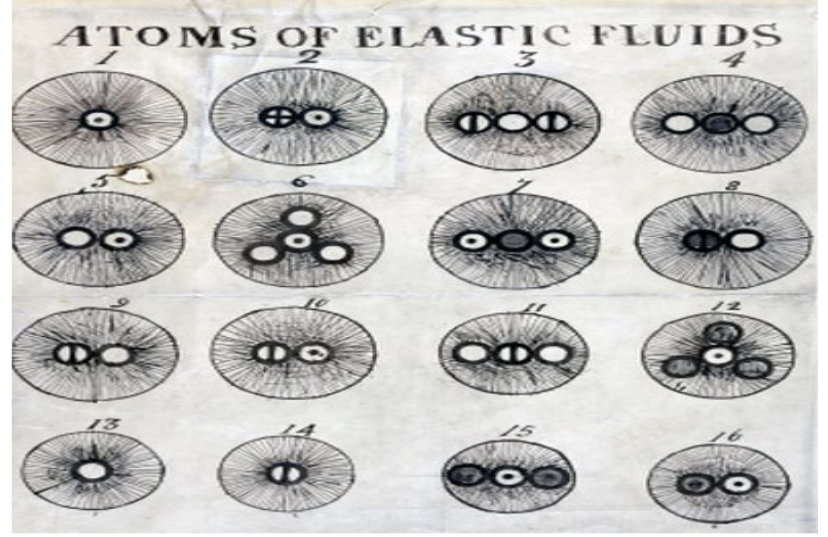

Fonte: Viana (2007, p. 64)

Essas novas concepções advindas dos estudos sobre o calórico permitiram a Dalton atribuir que os átomos possuiriam diferentes tamanhos de acordo com a quantidade de calórico que estaria em sua volta, ou seja, quanto maior seu calor específico, maior seria o átomo. Sendo assim, os átomos possuiriam a capacidade de absorver calor em uma determinada temperatura, o que explicaria a variação nos diâmetros, ou seja, o átomo que possuísse maior atração teria uma atmosfera mais densa e larga. Já aqueles com fraca atração teriam menor atmosfera e menor diâmetro (VIANA, 2007). Estas mudanças em seu modelo atômico resultaram na 
segunda teoria das misturas gasosas, que foi desenvolvida entre os anos de 1804 e 1805.

Para Viana e Porto (2007), a segunda teoria das misturas gasosas permitiu a Dalton estabelecer conexões entre as atmosferas calóricas dos átomos e suas massas:

\begin{abstract}
Os calores específicos de pesos iguais de quaisquer dois fluidos elásticos, são inversamente proporcionais aos pesos de seus átomos ou moléculas... Os calores específicos de iguais quantidades de fluidos elásticos, são diretamente proporcionais a suas gravidades especificas, e inversamente proporcionais aos pesos de seus átomos (DALTON, 1964, p.58 apud VIANA; PORTO, 2007, p.11).
\end{abstract}

Apesar de ser considerada atualmente incorreta, a segunda teoria das misturas gasosas era capaz de explicar as relações volumétricas que ocorriam em uma reação química. Sua teoria finalmente foi divulgada no livro "New System of Chemical Philosophy", em duas partes: a primeira no ano de 1808 e a segunda em 1810, ambas em Manchester e Londres, ganhando tradução para o idioma alemão anos depois (1812/1813) (MARR, 2011). Na obra "New System of Chemical Philosophy" foi publicado também o diagrama de representações atômicas para os elementos compostos, conforme mostra a Figura 4 (a seguir).

A lei das proporções múltiplas de Dalton contém traços das leis ponderais, sendo de fundamental importância na proposição dos pesos atômicos. Esse fato enaltece o poder de explicação da teoria de Dalton no aspecto quantitativo. A teoria atômica de Dalton foi capaz de explicar as combinações químicas, mesmo que de forma superficial, mediante a aplicação da lei das proporções múltiplas, sendo os átomos quantificados a partir de uma brilhante relação de massas atômicas relativas (VIANA, 2007). A Teoria Atômica de Dalton, após a teoria de Lavoisier, foi considerada como a pedra basilar da Química quantitativa. 
Figura 4: Diagrama representando os átomos de diferentes elementos e compostos

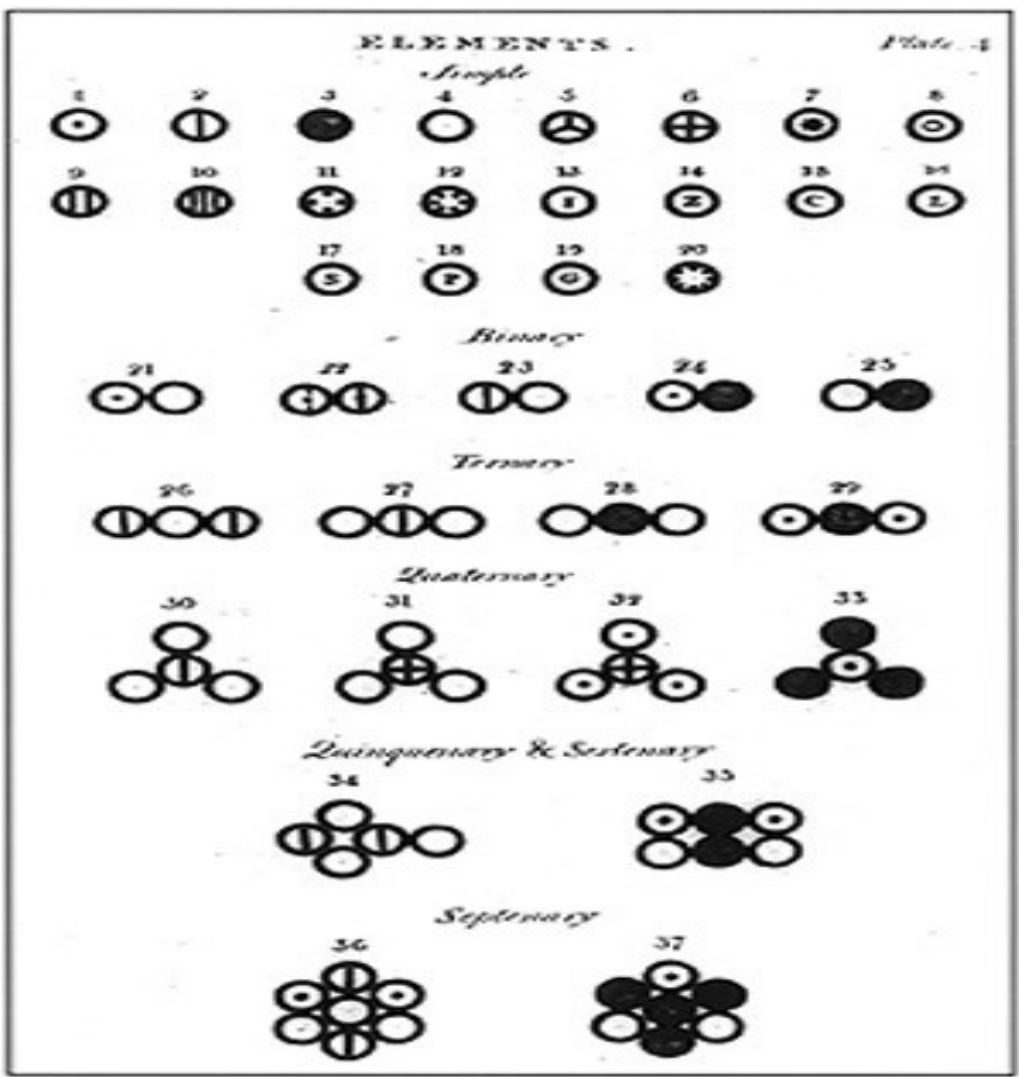

Fonte: Dalton (1964 [1808] apud VIANA, 2007, p.69)

O quadro a seguir (Quadro 3) traz a legenda para as representações de átomos apresentados na figura anterior.

Quadro 3: Legenda para o diagrama de representações de Dalton (Figura 4)

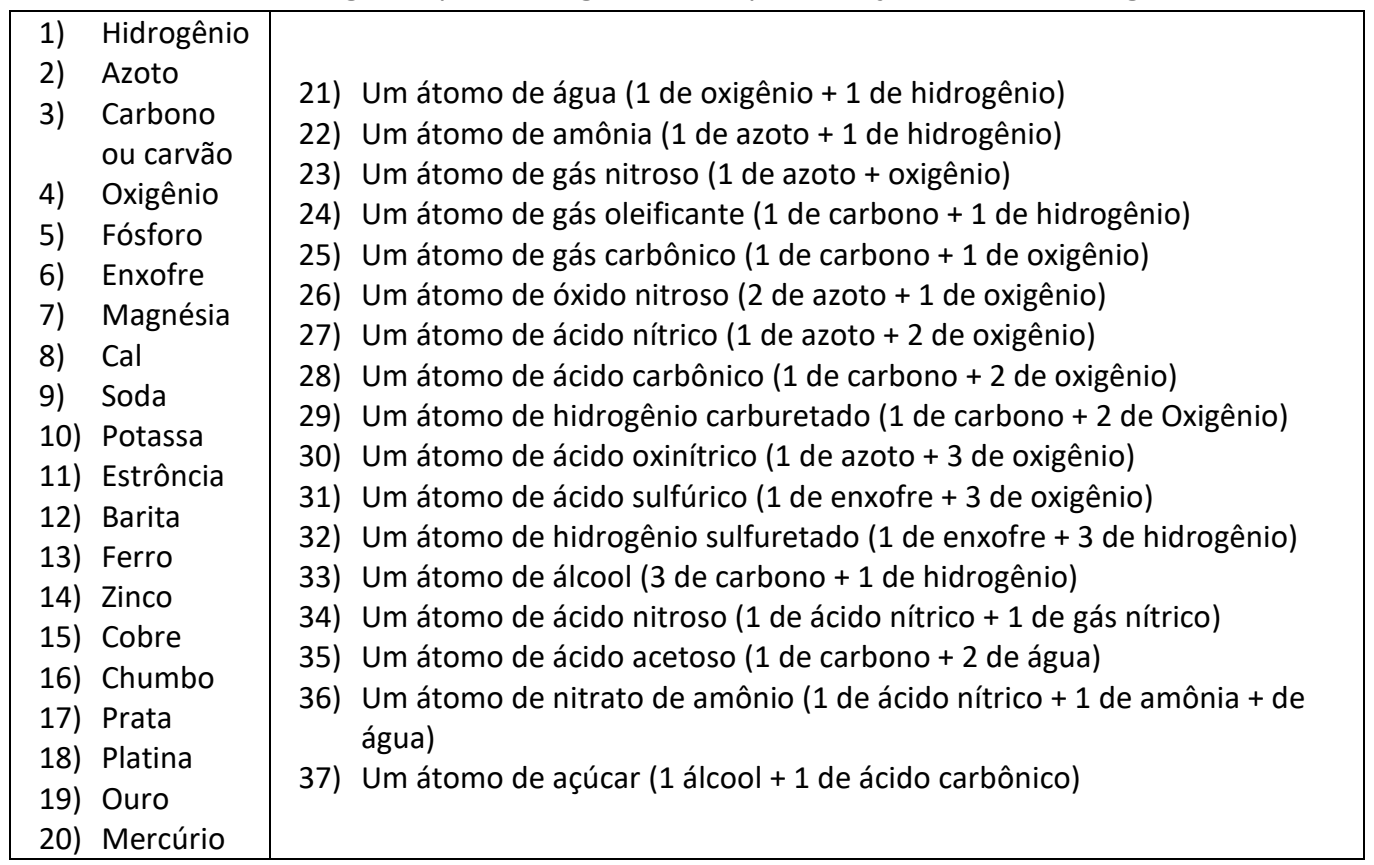




\section{CONTRIBUIÇÕES HISTÓRICAS PARA O ENSINO DO MODELO ATÔMICO DE DALTON}

Como destacado inicialmente, em geral, os materiais didáticos acabam influenciando os alunos a construir uma imagem errônea de ciência. A maioria dos materiais didáticos apontam que Dalton foi influenciado por concepções atomistas gregas, o que não ocorreu de forma direta.

Estes materiais também geralmente mostram apenas grandes descobertas científicas, sem valorizar o contexto histórico no qual conceito foi criado, passando a impressão que a ciência é feita por pessoas grandiosas alheias à influência de seu tempo. Assim, enaltecem "as grandes personalidades" que fizeram parte da história, sem contemplar os demais cientistas que contribuíram para a evolução de determinado tema, de modo que a ciência é vista como algo isolado e não em plena evolução, acarretando em uma perspectiva anacrônica e positivista.

Neste contexto, chama-nos à atenção um dos enunciados que os materiais de apoio atribuem como autoria de Dalton:

1) Os átomos são esféricos, maciços e indivisíveis

Esse postulado não foi elaborado durante a proposição do seu modelo atômico, sendo esse modelo visto exclusivamente em torno da constituição da matéria, o que não contempla sua principal contribuição à química, seu aspecto quantitativo. Estudando o contexto histórico em que o conceito átomo foi postulado, é possível compreender como ele foi evoluindo ao longo dos anos, como também verificar a contribuição de diversos cientistas para a proposição desse conceito. $O$ conceito de átomo foi instituído pelos atomistas gregos, no entanto, as concepções atomistas que influenciaram Dalton vieram das obras de Newton e Boyle, adeptos do pensamento atomista. Boyle acreditava na ideia de que a matéria era pequena e indivisível, além de afirmar que átomos de um mesmo elemento químico possuem o mesmo peso atômico. Muitos livros atribuem a autoria deste pensamento a Dalton, a partir de seus postulados. No entanto Dalton obteve essas concepções das obras de Newton, que foi consequentemente influenciado por Boyle.

A HFC possibilita compreender o contexto histórico em que o átomo foi postulado, levando o estudante às origens do conceito atômico, possibilitando entendermos quais conceitos científicos influenciaram Dalton em seus estudos, mostrando que a ciência não é algo pronto e acabado e sim em constante evolução ao longo da história. Ensinar os conceitos relacionados ao modelo atômico de Dalton via HFC pode auxiliar os professores a ensinarem os passos de como essa teoria foi realmente se estabelecendo, percorrendo os caminhos juntamente com os cientistas e filósofos na construção do conceito científico.

A contribuição de cada cientista na formulação do conceito modelo atômico mostra que a ciência não é feita apenas por grandes gênios, mas sim por um conjunto de pessoas, uma comunidade científica. Assim, a HFC pode auxiliar na problematização da visão distorcida acerca do desenvolvimento científico, como por exemplo, da concepção de que a Ciência é um empreendimento solitário.

O tipo de abordagem feita pelos materiais didáticos ainda proporciona uma ideia errônea sobre os objetivos de Dalton em relação ao modelo atômico. Muitas 
vezes esses materiais apresentam o modelo no interior de uma discussão sobre a constituição da matéria, engajando Dalton e seu modelo no interior dessa história, o que, de forma acrítica, parece ligar o cientista à pretensão da instituição de um modelo atômico. Valendo-se da estrutura de postulados, tal instituição parece ainda completamente racionalista. Assim, o aspecto quantitativo, sua principal contribuição à história do átomo é deixada de lado.

A abordagem histórica possibilita evidenciar que, contra um Dalton racionalista e interessado nos aspectos primordiais da matéria, o inglês se engaja à ciência a partir meteorologia. Em sua infância descreve o comportamento da aurora boreal, um de seus primeiros estudos, o qual se deu por via empírica. Adulto, adepto das concepções atomistas advindas do pensamento newtoniano, busca respostas para as diferentes solubilidades dos gases em água. Esse cientista procura então compreender as alterações dos fluidos gasosos na atmosfera, estudos muito semelhantes às pesquisas propostas por Henry que investigava o comportamento dos gases. Dessa forma, tem-se que destacar a importância dos estudos sobre a solubilidade dos gases de seu amigo Henry, pois os mesmos caracterizaram os estudos inicias rumo ao modelo atômico de Dalton.

Nesse sentido, é importante que os professores proponham práticas experimentais que relacionem o modelo atômico de Dalton ao estudo de solubilidade dos gases, pois esses foram de fundamental importância para a teoria. Isto proporcionaria ao estudante uma maior interação com o objeto de estudo do próprio Dalton. Quando Dalton realiza experimentos sobre a solubilidade dos gases em água, adepto às concepções atomistas, se pergunta se a diferença entre as massas das últimas partículas da matéria não seria o motivo dos gases apresentarem diferentes solubilidades em água. E vista disso, a proposição do modelo atômico de Dalton ganha aspecto materialista ao mesmo tempo em que se estrutura a partir de dados experimentais.

Para além do modelo atômico exclusivamente, o estudo sobre a solubilidade dos gases permite a Dalton e Henry formularem várias teorias e leis importantes para o desenvolvimento da ciência, como: lei das pressões parciais; lei de Henry; primeira teoria das misturas gasosas.

Esses fatos mostram duas coisas importantes, as quais os materiais didáticos não enfatizam:

1. O modelo atômico de Dalton foi proveniente de um ponto de vista material e experimental;

2. Os principais objetivos desse modelo estão nos aspectos quantitativos da solubilidade dos gases e não em definir a estrutura primordial da matéria.

Dalton, movido por uma busca às respostas, chega à relação de massas atômicas relativas propondo sua primeira tabela de pesos atômicos. Surge a necessidade de Dalton propor uma tabela de pesos atômicos e utilizar símbolos para separar os elementos. A partir da leitura do texto historiográfico apresentado é possível entendermos os motivos que levaram Dalton a propor seu simbolismo, diferentemente de outras obras que apenas o inserem sem apresentar seu contexto.

Após propor a tabela de pesos relativos e propor símbolos para identificar os elementos, Dalton propõe a lei das proporções múltiplas, a qual possibilita ao professor discutir os conceitos de substância simples e composta. A lei das 
proporções múltiplas foi de fundamental importância para a ciência, pois possibilitou a identificação de novas substâncias. Somente por meio de um estudo historiográfico somos capazes de compreender o processo de como Dalton propôs esta lei.

Isto posto, a inserção de elementos de HFC no ensino do modelo atômico de Dalton fornece ao professor diversas ferramentas, factuais, históricas, conceituais e experimentais para o trabalho em sala de aula, tornando o processo de ensino e aprendizagem mais atrativo para os alunos, proporcionando uma melhor compreensão dos conceitos envolvidos.

\section{CONSIDERAÇÕES FINAIS}

Em meio às dificuldades destacadas no ensino de Química, em que o atomismo é encarado como algo abstrato pelos alunos, espera-se que a partir dos elementos histórico-filosóficos aqui destacados, os alunos compreendam as contribuições do modelo de Dalton para o desenvolvimento da Ciência, contribuindo com os processos de ensino e aprendizagem.

Utilizando a historiografia da Ciência, a fim de obter fontes confiáveis, é esperado que os alunos compreendam que Dalton possuía dificuldades e limitações, mas que por meio de sua perspicácia propôs um modelo que mudou a história e o desenvolvimento da Química. Dessa forma, é desejado que a Ciência seja desmistificada, a partir de uma perspectiva mais humana.

Diante do exposto, espera-se que o ensino via HFC conduza os estudantes a relacionar leis, princípios, proporcionando condições para que sejam capazes de compreender os conceitos envolvidos, desenvolvendo suas habilidades, atitudes e competências, contribuindo para a reflexão sobre os conceitos e as situações propostas ao longo do processo de ensino e aprendizagem.

É evidente que precisamos de ferramentas e novos métodos para mobilizar os alunos e mudar o atual cenário do ensino de Química no Brasil. E é nessa direção que essa proposta visa contribuir, apresentando um novo material de apoio aos professores do Ensino Médio. Porém, para que esse tipo de abordagem se torne recorrente e produza resultados efetivos na Educação Básica, é necessária uma formação docente - inicial e continuada - que forme o professor para o trabalho nessa perspectiva.

Assim, essa proposta pode contribuir como aporte teórico, indicando caminhos para a formação de futuros professores e professores em atividade, a fim de desmistificar o papel da História da Ciência e sua articulação com o ensino dos conceitos científicos.

Concluindo, essa proposta pode contribuir mostrando aos futuros professores e aos profissionais em atividade a importância de se utilizar a História da Ciência, visando o desenvolvimento de um ensino que seja mais próximo e significativo para o aluno. 


\title{
Historical-philosophical subsidies for the teaching of the Dalton atomic model
}

\begin{abstract}
The objective of this work is to seek subsidies in the history and philosophy of science for the teaching of the atomic model of Dalton as a contribution to change the current educational scenario, seen as "abstract" by the majority of students. Using the historiography of science, the main historical aspects of the constitution of Dalton's atomic model were raised, pointing out the main concepts that must be worked through a historical approach to make the teaching and learning process closer and more meaningful for the student. The results show the necessity of aproach on prior historical and conceptual aspects to the Dalton's propositions, as well as the discussion of experiments related to the study of gases which led the scientist to the proposition of a quantitative perspective for the atomic constitution of matter. The study concludes that beyond the importance of Dalton as a proposer of a quantitative perspective, there's the necessity of his transformation into an heir and defender of a long history of concepts about matter.
\end{abstract}

KEYWORDS: Chemistry teaching. The atomic model of Dalton. History of Science. 


\section{REFERÊNCIAS}

ALFONSO-GOLDFARB, A. M.; FERRAZ, M. H. M.; BELTAN, M. H. R.; PORTO, A. P. Percursos de História da Química. Coleção temas de História da Ciência, São Paulo, Editora Livraria da Física, 2016.

BENSAUDE-VICENT, B.; STENGERS, I. História da Química. Instituto Piaget, Lisboa, 1992.

BRASIL, MEC. As Novas Diretrizes Curriculares que Mudam o Ensino Médio Brasileiro, Brasília, 2002.

BRASIL, MEC. Parâmetros Curriculares Nacionais - Ensino Médio, Brasília, 2000.

CAMPOS, R. C.; SILVA, R. C. De massas e massas atômicas. Química nova na escola, n. 19, p.8-10, 2004.

FILGUEIRAS, C. A. L. Duzentos anos da teoria atômica de Dalton. Química nova na escola, n. 20, p. 38-44, 2004.

FRANÇA, A. C. G.; MARCONDES, E. R.; CARMO, M. P. Estrutura Atômica e Formação dos Íons: Uma Análise das Ideias dos Alunos do 3ำ Ano do Ensino Médio. Química nova na escola, n. 31, p. 275-282, 2009.

KRAGH, Helge. Introdução à Historiografia da Ciência. Portugal, Editora Porto, 2001.

MARR, J. H. História da Química - Primeira parte- Dos primórdios a Lavoisier. Florianópolis, Conceito Editorial, 2008.

MARR, J. H. História da Química - Segunda Parte - De Lavoisier ao sistema periódico. Florianópolis, Editora Papa-livro, 2011.

MARTINS, A.F.P. História e Filosofia da Ciência No Ensino: Há Muitas Pedras Nesse Caminho. Caderno Brasileiro de Ensino de Física, v. 24, n. 1, p. 112-131, 2007.

MELO, M. R.; LIMA-NETO, E. G. Dificuldades de Ensino e Aprendizagem dos Modelos Atômicos em Química. Química nova na escola, v. 35, n. 2, p. 112-122, 2013. 
MIRANDA, C. L.; PEREIRA, C. S.; MATIELLO, J. R.; REZENDE, D. B. Modelos

Didáticos e Cinética Química: Considerações sobre o que se Observou nos Livros Didáticos de Química Indicados pelo PNLEM. Química nova na escola, v. 37, n.3, p. 197-203, 2015.

MORTIMER, E. F. As concepções atomistas dos estudantes. Química nova na escola, n. 1, p. 23-26, 1995.

NUNES, A. S.; ADORNI, D.S. O ensino de química nas escolas da rede pública de ensino fundamental e médio do município de Itapetinga-BA: $O$ olhar dos alunos. In: Encontro Dialógico Transdisciplinar - Enditrans, 2010, Vitória da Conquista, BA. - Educação e conhecimento científico, 2010.

OLIVEIRA, S. F. MELO, N. F.; SILVA, T.; VASCONCELOS, E. A. Softwares de Simulação no Ensino de Atomística: Experiências Computacionais para Evidenciar Micromundos. Química nova na escola, v. 35, n.3, p. 147-151, 2013.

PEREIRA, L. L. S.; BENITE, C. R. M.; BENITE, A. M. C. Aula de Química e Surdez: sobre Interações Pedagógicas Mediadas pela Visão. Química nova na escola, v. 33, n.1, p. 47-56, 2011.

QUADROS, A. L. et al. Ensinar e aprender Química: a percepção dos professores do Ensino Médio. Educação em Revista, n. 40, 2011.

RIBEIRO, E.N.C; ROCHA, R.G.C; BRUNO, R. As transições eletrônicas no átomo de Bohr como uma proposta de atividade para abordar tópicos de Física moderna e contemporânea nas Escolas do Século XXI. Revista práxis edição especial, iv simpósio em ensino de ciências e meio ambiente do rio de janeiro | ano vii | jun. de 2015.

RIBEIRO, W. H. F.; MESQUITA, J. M. Um olhar reflexivo sobre a realidade das aulas de química em uma escola pública cearense. Revista Essentia, Sobral, v. 13, n.2, p. 165-183, 2012.

SANTOS, A. O.; SILVA, R. P.; ANDRADE, D.; LIMA, J. P. M. Dificuldades e motivações de aprendizagem em Química de alunos do ensino médio investigadas em ações do (PIBID/UFS/Química). Scientia Plena, v. 9, n. 7, 2013.

SILVA, G. R.; MACHADO, A. H.; SILVEIRA, K. P. Modelos para o Átomo: Atividades com a Utilização de Recursos Multimídia. Química nova na escola, v. 37, n. 2, p. 106-111, 2015. 
STRATHERN, P. Uma fórmula para a Química: In: O sonho de

Mendeleiev: a verdadeira história da Química. Rio de Janeiro: Zahar Editora, p.

208-217, 2002.

VIANA, H. E. A Construção da Teoria Atômica de Dalton como Estudo de Caso e Algumas Reflexões para o Ensino de Química. 106f. Dissertação (Mestrado em Ensino de Ciências) Universidade de São Paulo, São Paulo, 2007.

VIANA, H. E. B.; PORTO, P. A. O processo de elaboração da teoria atômica de Dalton. Química nova na escola, n. 7, p. 4-12, 2007.

VIDEIRA, A. A. P. Historiografia e história da ciência. Escritos. Revista da Fundação Casa de Rui Barbosa, n. 1, p. 284, 2007.

Recebido: 29 mai. 2017

Aprovado: 21 ago. 2017

DOI: $10.3895 /$ actio.v2n1.6779

Como citar:

GATTO, M. A.; SUART JÚNIOR, J. B.; STANZANI, E. de L. Subsídios histórico-filosóficos para o ensino do modelo átomo de Dalton. ACTIO, Curitiba, v. 2, n. 1, p. 376-400, jan./jul. 2017. Disponível em:

$<$ https://periodicos.utfpr.edu.br/actio>. Acesso em: XXX.

Correspondência:

Marcos Antônio Gatto

Rua Denhei Kanashiro, n.163, Jardim Aeroporto, Apucarana, Paraná, Brasil.

Direito autoral: Este artigo está licenciado sob os termos da Licença CreativeCommons-Atribuição 4.0

Internacional.

(c) (i) 